\title{
Role of reactive species in the photocatalytic degradation of amaranth by highly active $\mathrm{N}$-doped $\mathrm{WO}_{3}$
}

\author{
HANGGARA SUDRAJAT and SANDHYA BABEL* \\ School of Biochemical Engineering and Technology, Sirindhorn International Institute of Technology, Thammasat \\ University, Pathum Thani 12121, Thailand \\ *Author for correspondence (sandhya@ siit.tu.ac.th)
}

MS received 27 July 2016; accepted 7 April 2017; published online 6 December 2017

\begin{abstract}
A novel, highly visible light active $\mathrm{N}$-doped $\mathrm{WO}_{3}\left(\mathrm{~N}-\mathrm{WO}_{3}\right)$ is successfully synthesized via thermal decom-

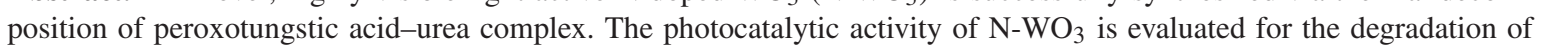
amaranth (AM) dye under visible and UVA light along with the role of reactive species, which has not yet been studied for $\mathrm{N}-\mathrm{WO}_{3}$ photocatalysts. Doping of $\mathrm{N}$ into substitutional and interstitial sites of $\mathrm{WO}_{3}$ is confirmed by X-ray photoelectron spectroscopy and X-ray absorption near-edge spectroscopy. At a $\mathrm{pH}$ of $7,1 \mathrm{~g}^{-1}$ of $\mathrm{N}-\mathrm{WO}_{3}$ can completely degrade $10 \mathrm{mg}^{-1}$ of AM within $1 \mathrm{~h}$ under visible and UVA light. For the degradation of $\mathrm{AM}$ by $\mathrm{N}-\mathrm{WO}_{3}$ under visible and UVA light, $\mathrm{h}^{+}$is found to be the main reactive species, while ${ }^{\circ} \mathrm{OH}$ contributes to a lesser extent. On the contrary, ${ }^{1} \mathrm{O}_{2},{ }^{\bullet} \mathrm{O}_{2}^{-}$and $\mathrm{e}^{-}$ show negligible roles. The crucial role of $\mathrm{h}^{+}$indicates effective suppression of electron-hole recombination after $\mathrm{N}$ doping. Dye sensitization and oxidation by reactive species are found to be the major pathway for the degradation of AM under visible and UVA light, respectively.
\end{abstract}

Keywords. Nitrogen doping; photocatalysis; visible light active; reactive species; amaranth.

\section{Introduction}

Over the past decade, advanced oxidation processes (AOPs), which are capable of generating various reactive radicals, have been proposed for the degradation of toxic and/or recalcitrant compounds in wastewaters. Among AOPs, semiconductor photocatalysis have received great attention due to its clean and solar-driven process, versatility and low-cost of operation at mild conditions.

Of a variety of semiconductors, tungsten oxide $\left(\mathrm{WO}_{3}\right)$ seems suitable as it posseses narrow band gap, very deep valence band (VB) potential and high stability [1-3]. However, despite its ability to effectively absorb visible light, pristine $\mathrm{WO}_{3}$ shows poor visible light activity. This is because its conduction band (CB) potential is very low [4-9]. Thus, the photogenerated electrons, accumulated in the $\mathrm{CB}$ cannot be consumed by electron acceptors, resulting in fast recombination with the holes in the VB. It is seen that visible light absorption of $\mathrm{WO}_{3}$ does not necessarily lead to visible light activity.

To increase the visible light response and the visible light activity of $\mathrm{WO}_{3}, \mathrm{~N}$ doping appears to be a promising strategy. $\mathrm{N}$ can introduce a new energy level within the band gap, thereby extending the spectral response to longer wavelengths and prevents an electron-hole pair from recombination by trapping the electron, thereby increasing photocatalytic activity. Its similar size with $\mathrm{O}$ and its lower electronegativity than that of $\mathrm{O}$ may also enable homogeneous doping of $\mathrm{N}$ within the doped matrix.

The key factor controlling the efficiency of photocatalytic degradation of organic compounds is the type of reactive species generated upon irradiation. However, this aspect has not yet been studied for $\mathrm{N}-\mathrm{WO}_{3}$ photocatalysts. Therefore, in this research, the role of reactive species on the degradation of amaranth (AM), a recalcitrant organic compound, by $\mathrm{N}$-doped $\mathrm{WO}_{3}\left(\mathrm{~N}-\mathrm{WO}_{3}\right)$ under visible and UVA light is investigated. A mechanism of AM degradation by $\mathrm{N}-\mathrm{WO}_{3}$ is proposed. The effects of operating parameters and inorganic ions are also studied.

\section{Materials and methods}

\subsection{Materials}

All chemicals were of analytical grade. Tungstic acid $\left(\mathrm{H}_{2} \mathrm{WO}_{4}\right.$, Aldrich), hydrogen peroxide solution $\left(\mathrm{H}_{2} \mathrm{O}_{2}, 35\right.$ wt $\%$, Aldrich), urea $\left(\mathrm{CO}\left(\mathrm{NH}_{2}\right)_{2}\right.$, Aldrich), AM $\left(\mathrm{C}_{20} \mathrm{H}_{11}\right.$ $\mathrm{N}_{2} \mathrm{Na}_{3} \mathrm{O}_{10} \mathrm{~S}_{3}$, Aldrich), commercial $\mathrm{WO}_{3}$ (Aldrich), potassium iodide (KI, Aldrich), isopropanol $\left(\left(\mathrm{CH}_{3}\right)_{2} \mathrm{CHOH}\right.$, Aldrich), sodium azide $\left(\mathrm{NaN}_{3}\right.$, Aldrich), 2-chloroethanol $\left(\mathrm{Cl}\left(\mathrm{CH}_{2}\right)_{2} \mathrm{OH}\right.$, Aldrich), $p$-benzoquinone $\left(\mathrm{C}_{6} \mathrm{H}_{4} \mathrm{O}_{2}\right.$, Aldrich $)$, sodium chloride $(\mathrm{NaCl}$, Chameleon reagent), sodium nitrate $\left(\mathrm{NaNO}_{3}\right.$, Aldrich), sodium carbonate $\left(\mathrm{Na}_{2} \mathrm{CO}_{3}\right.$, Chameleon 
reagent), sodium sulphate $\left(\mathrm{Na}_{2} \mathrm{SO}_{4}\right.$, Chameleon reagent), ammonium sulphate $\left(\left(\mathrm{NH}_{4}\right)_{2} \mathrm{SO}_{4}\right.$, Chameleon reagent $)$ and calcium sulphate $\left(\mathrm{CaSO}_{4}\right.$, Chameleon reagent) were used as received without further purification. Milli-Q water was used in all the processes.

\subsection{Synthesis}

$\mathrm{N}-\mathrm{WO}_{3}$ was synthesized by thermal decomposition of peroxotungstic acid-urea complex. The peroxotungstic acid was obtained through the reaction of $\mathrm{H}_{2} \mathrm{WO}_{4}$ with $\mathrm{H}_{2} \mathrm{O}_{2}$. About $3.75 \mathrm{~g}$ of $\mathrm{H}_{2} \mathrm{WO}_{4}$ was dispersed in $75 \mathrm{ml}$ of water with continuous stirring followed by addition of $25 \mathrm{ml}$ of aqueous $\mathrm{H}_{2} \mathrm{O}_{2}$ into the dispersion. The reaction mixture was then stirred for $24 \mathrm{~h}$ at $40^{\circ} \mathrm{C}$. After drying, the obtained powder was dissolved in $75 \mathrm{ml}$ of hot water with continuous stirring for $1 \mathrm{~h}$ at $75^{\circ} \mathrm{C}$. The solid product was subsequently ground with $1.8 \mathrm{~g}$ of $\mathrm{CO}\left(\mathrm{NH}_{2}\right)_{2}$ in an agate mortar for $30 \mathrm{~min}$. The ground mixture was calcined at $500^{\circ} \mathrm{C}$ for $3 \mathrm{~h}$ in a muffle furnace to form crystalline $\mathrm{N}-\mathrm{WO}_{3}$ with orange-red colour. The $\mathrm{N}-\mathrm{WO}_{3}$ was washed with water followed by ethanol prior to drying at $100^{\circ} \mathrm{C}$ for $24 \mathrm{~h}$. Furthermore, pristine $\mathrm{N}-\mathrm{WO}_{3}$ was synthesized by the same method without adding urea. For comparative purposes, $\mathrm{N}-\mathrm{WO}_{3}$ was also synthesized using a similar manner but with commercial $\mathrm{WO}_{3}\left(\mathrm{c} / \mathrm{WO}_{3}\right)$ as starting material, which is denoted as $\mathrm{c} / \mathrm{N}-\mathrm{WO}_{3}$. About $3.48 \mathrm{~g}$ of $\mathrm{c} / \mathrm{WO}_{3}$ was ground with $1.8 \mathrm{~g}$ of $\mathrm{CO}\left(\mathrm{NH}_{2}\right)_{2}$ in an agate mortar for 30 min followed by calcination, washing and drying.

\subsection{Characterization}

The infrared spectra were recorded by a Fourier transform infrared spectrometer (FT-IR-610, Jasco). The X-ray diffraction (XRD) patterns were collected on a Bruker D8 diffractometer $(\mathrm{Cu} \mathrm{K} \alpha$ radiation, $\lambda=1.5406 \AA)$. The morphological properties were observed by transmission electron microscopy (JEM 2100, Jeol). The textural properties were examined using $\mathrm{N}_{2}$ adsorption-desorption isotherms at the liquid nitrogen temperature of $77 \mathrm{~K}$ by an adsorption instrument (Belsorp 28SA, Bel). The diffuse reflectance spectra were obtained from a UV-Vis-NIR spectrophotometer (Cary 5000, Agilent) with $\mathrm{BaSO}_{4}$ as reflectance standard. The chemical state of $\mathrm{N}$ dopant was verified by $\mathrm{X}$-ray photoelectron spectroscopy (XPS) (Axis Ultra DLD, Kratos Analytical) with $\mathrm{Al} \mathrm{K} \alpha$ radiation and $\mathrm{X}$-ray absorption near-edge spectroscopy (XANES) at Beamline 3.2a of the Synchrotron Light Research Institute (public organization), Thailand. The zeta potentials were measured as a function of $\mathrm{pH}$ using an electrophonic light scattering spectrophotometer (ELS-8000, Otsuka).

\subsection{Photocatalytic activity evaluation}

The photocatalytic activity of the catalyst was evaluated by the degradation of AM under visible and UVA light. A 100 $\mathrm{ml}$ of suspension containing known concentrations of the dye and the catalyst was transferred into a batch photoreactor. Dilute $\mathrm{NaOH}$ and $\mathrm{HCl}$ were used to adjust the suspension $\mathrm{pH}$ to a desired level. To attain adsorption-desorption equilibrium, the suspension was magnetically stirred at $200 \mathrm{rpm}$ in the dark for $2 \mathrm{~h}$. A metal halide lamp $160 \mathrm{~W}$ (Philips), with an irradiance of $144.7 \mathrm{~W} \mathrm{~m}^{-2}$ and a blacklight lamp $13 \mathrm{~W}$ (General Electric) with an irradiance of $3.5 \mathrm{~W} \mathrm{~m}^{-2}$ were used as visible and UVA light sources, respectively. The metal halide lamp was equipped with a cut-off filter, removing radiation below $400 \mathrm{~nm}$. The lamp was switched on to initiate a photocatalytic reaction. After a given irradiation time, the suspension was withdrawn and centrifuged to measure the absorbance of AM solution at $\lambda_{\max }$ of $521 \mathrm{~nm}$ by using a UVvis spectrophotometer (UH 5300, Hitachi). To determine the dye concentration, calibration plots based on Beer-Lambert's law were established by relating the absorbance to the concentration. The dye degradation efficiency (DE) is calculated from the equation (1) [10]:

$$
\mathrm{DE}(\%)=\left(\frac{C_{0}-C}{C_{0}}\right) \times 100,
$$

where $C_{0}$ and $C$ are the AM concentrations at equilibrium and after irradiation $\left(\mathrm{mg} \mathrm{l}^{-1}\right)$, respectively. Control experiments in the absence of a catalyst were carried out with continuous stirring for $6 \mathrm{~h}$. AM is found to be stable upon visible and UVA irradiation resulting in photolysis of less than $5 \%$.

In order to find out the reactive species responsible for the degradation of AM, a series of quenchers were used to scavenge the reactive species. Different amount of quenchers were introduced into the $\mathrm{AM}$ solution before catalyst addition. $\mathrm{KI}\left(0.1 \mathrm{~g} \mathrm{l}^{-1}\right),\left(\mathrm{CH}_{3}\right)_{2} \mathrm{CHOH}\left(1 \mathrm{~g} \mathrm{l}^{-1}\right), \mathrm{NaN}_{3}\left(0.01 \mathrm{~g} \mathrm{l}^{-1}\right)$, $\mathrm{Cl}\left(\mathrm{CH}_{2}\right)_{2} \mathrm{OH}\left(0.36 \mathrm{~g} \mathrm{l}^{-1}\right)$ and $\mathrm{C}_{6} \mathrm{H}_{4} \mathrm{O}_{2}\left(0.02 \mathrm{~g} \mathrm{l}^{-1}\right)$ were used to quench $\mathrm{h}^{+},{ }^{\bullet} \mathrm{OH},{ }^{1} \mathrm{O}_{2}, \mathrm{e}^{-}$and ${ }^{\circ} \mathrm{O}_{2}^{-}$, respectively [10]. In the presence of quenchers, the degradation of AM is suppressed to a certain extent and the decreased apparent first order rate constant $\left(k_{\text {app }}\right)$ is observed. The $k_{\text {app }}$ is determined based on the apparent pseudo-first-order kinetic model according to equation (2):

$$
\ln \left(\frac{C_{0}}{C}\right)=k_{\mathrm{app}} t
$$

The more the $k_{\text {app }}$ is decreased, the more vital the role of the reactive species. The role of the reactive species was indicated by $R(\%)$, according to equation (3):

$$
R(\%)=\left(\frac{k_{\mathrm{app}}-k_{\mathrm{app}}^{\prime}}{k_{\mathrm{app}}}\right) \times 100,
$$

where $k_{\text {app }}^{\prime}$ is the $k_{\text {app }}$ in the presence of quencher.

To study the effect of operating parameters on the AM degradation by $\mathrm{N}-\mathrm{WO}_{3}$, the experiments were performed by 
Table 1. Properties of the prepared catalysts.

\begin{tabular}{|c|c|c|}
\hline & $\mathrm{WO}_{3}$ & $\mathrm{~N}-\mathrm{WO}_{3}$ \\
\hline Crystalline phase & Monoclinic & Monoclinic \\
\hline Crystalline size $(\mathrm{nm})^{\mathrm{a}}$ & 37.4 & 17.1 \\
\hline Band gap $(e V)^{b}$ & 2.66 & 2.58 \\
\hline XPS peak of $N(e V)$ & Not detected & $397.6(\mathrm{~W}-\mathrm{N}), 400(\mathrm{~N}-\mathrm{N} ; \mathrm{N}-\mathrm{O})$ \\
\hline XANES peak of N (eV) & Not detected & $\begin{array}{l}400.6\left(1 \mathrm{~s} \rightarrow \pi^{*} \text { transitions }\right) \\
408\left(1 \mathrm{~s} \rightarrow \sigma^{*} \text { transitions }\right)\end{array}$ \\
\hline Specific surface area $\left(\mathrm{m}^{2} \mathrm{~g}^{-1}\right)^{\mathrm{c}}$ & 10.7 & 14.3 \\
\hline Average pore diameter $(\mathrm{nm})^{\mathrm{d}}$ & 1.64 & 10.65 \\
\hline Pore volume $\left(\mathrm{cm}^{3} \mathrm{~g}^{-1}\right)^{\mathrm{d}}$ & 0.113 & 0.110 \\
\hline $\mathrm{pH}_{\mathrm{zpc}}$ & 1.9 & 2.1 \\
\hline
\end{tabular}

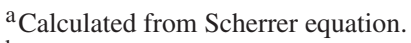

${ }^{\mathrm{b}}$ Calculated by Tauc's method.

${ }^{\mathrm{c}}$ Determined based on the Brunauer-Emmett-Teller isotherm.

${ }^{\mathrm{d}}$ Calculated from the Barrett-Joyner-Halenda isotherm.

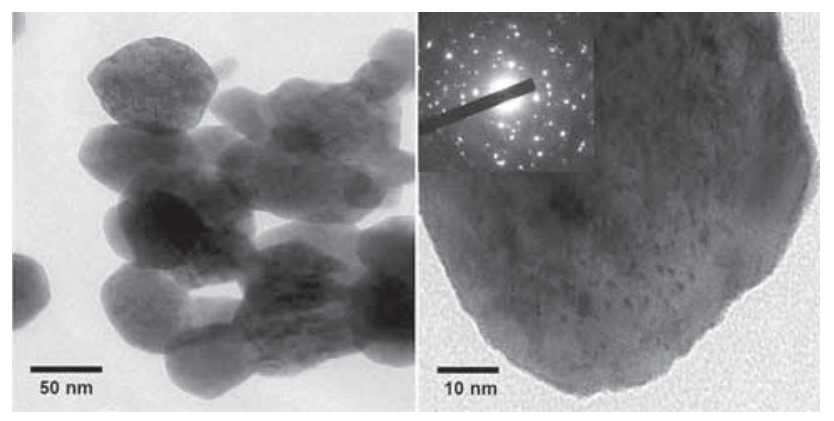

Figure 1. TEM images of $\mathrm{N}-\mathrm{WO}_{3}$ with electron diffraction pattern.

varying key operating parameters, namely, dye concentration $\left(5-25 \mathrm{mg} \mathrm{l}^{-1}\right)$, catalyst concentration $\left(0.5-2.5 \mathrm{~g} \mathrm{l}^{-1}\right)$, $\mathrm{pH}(5-9)$ and $\mathrm{H}_{2} \mathrm{O}_{2}$ concentration $\left(0.1-0.7 \mathrm{~g}^{-1}\right)$.

The effects of anions and cations on the photocatalytic degradation of $\mathrm{AM}$ by $\mathrm{N}-\mathrm{WO}_{3}$ was investigated by the addition of sodium and sulphate salts, respectively, with a concentration of $0.1 \mathrm{M}$. Sodium salts were used to avoid the simultaneous effects of cations since $\mathrm{Na}^{+}$is at its maximum oxidation state and thus does not compete as a hole scavenger. In addition, $\mathrm{Na}^{+}$at concentrations of less than $0.1 \mathrm{M}$ should not affect the charge at the catalyst surface [11]. Sulphate salts were used due to their negligible effect on the photocatalytic activity of $\mathrm{N}-\mathrm{WO}_{3}$.

\section{Results and discussion}

\subsection{Catalyst properties}

Table 1 summarizes the properties of the catalysts. Compared to $\mathrm{WO}_{3}, \mathrm{~N}-\mathrm{WO}_{3}$ has higher specific surface area, lower

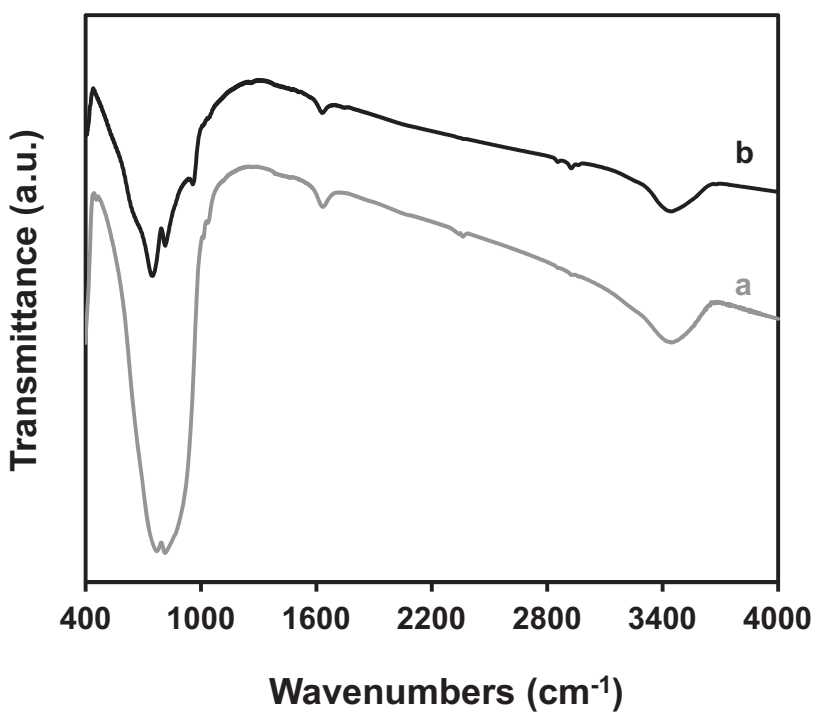

Figure 2. FTIR spectra of (a) $\mathrm{WO}_{3}$ and (b) $\mathrm{N}-\mathrm{WO}_{3}$.

crystalline size and lower band gap. On the basis of these properties, $\mathrm{N}-\mathrm{WO}_{3}$ is expected to exhibit a higher photocatalytic activity. Furthermore, as shown in figure 1, the diameter of primary particles of $\mathrm{N}-\mathrm{WO}_{3}$ is in the range of $30-70 \mathrm{~nm}$. XPS analysis confirms the presence of $\mathrm{W}-\mathrm{N}$ bond at $397.6 \mathrm{eV}$ and $\mathrm{N}-\mathrm{O}$ or $\mathrm{N}-\mathrm{N}$ bond at $400 \mathrm{eV}$, while XANES analysis confirms the presence of $\mathrm{N}_{2}$-like species at $400.6 \mathrm{eV}$.

The infrared spectra of the catalysts are shown in figure 2. The peaks at around $3440 \mathrm{~cm}^{-1}$ are assigned to the $\mathrm{O}-\mathrm{H}$ stretching modes of adsorbed water and the peak around $1630 \mathrm{~cm}^{-1}$ is assigned to the $\mathrm{O}-\mathrm{H}$ bending of the adsorbed water [12]. The peak centred at $956 \mathrm{~cm}^{-1}$ in the $\mathrm{WO}_{3}$ spectrum is probably due to the vibrations of adsorbed water. Moreover, the strong, broad peak in the fingerprint region of $500-900 \mathrm{~cm}^{-1}$ is assigned to the $\mathrm{W}-\mathrm{O}$ stretching modes [12]. As can be seen, the $\mathrm{W}-\mathrm{O}$ stretching modes are less intense 
for $\mathrm{N}-\mathrm{WO}_{3}$ and the peak is also slightly shifted to a lower wavenumber. This can be an indication of lattice structure alteration after doping with $\mathrm{N}$.

\subsection{Adsorption of $A M$}

Adsorption of AM on the catalyst is conducted in the absence of light at room temperature. As can be seen in table 2, less than $6 \%$ of $\mathrm{AM}$ is adsorbed within $1 \mathrm{~h}$ under dark condition. Although the difference of the specific surface area between $\mathrm{WO}_{3}$ and $\mathrm{N}-\mathrm{WO}_{3}$ is not significant, the ability of $\mathrm{N}-\mathrm{WO}_{3}$ to adsorb AM is two times higher than that of $\mathrm{WO}_{3}$. This is likely due to much higher availability of surface functional groups in $\mathrm{N}-\mathrm{WO}_{3}$. Indeed, the specific surface area usually plays a vital role on the adsorption extent. However, the availability of functional groups on the catalyst surface is also an important factor and determines the adsorption ability of the catalyst.

\subsection{Comparative photocatalytic degradation of $A M$}

The comparative degradation of AM over time by $\mathrm{WO}_{3}$, $\mathrm{N}-\mathrm{WO}_{3}, \mathrm{c} / \mathrm{WO}_{3}$ and $\mathrm{c} / \mathrm{N}-\mathrm{WO}_{3}$ is summarized in table 2 . The photocatalytic activity of $\mathrm{WO}_{3}$ is found to be higher than that of $\mathrm{c} / \mathrm{WO}_{3}$. This may be attributed to the difference in the band gap energy, the availability of surface functional groups and the specific surface area. The doped catalysts show better photocatalytic activity than the pristine counterpart. Moreover, c/N-WO $\mathrm{WO}_{3}$ exhibits lower photocatalytic activity than $\mathrm{N}-\mathrm{WO}_{3}$. This is presumably due to ineffective incorporation of $\mathrm{N}$ in the $\mathrm{WO}_{3}$ lattice. In $\mathrm{c} / \mathrm{N}-\mathrm{WO}_{3}$, the $\mathrm{N}$ dopants may only reside on the surface instead of in the bulk of the catalyst particles. Furthermore, DE under visible light is comparable to that under UVA light because under visible light AM can also be self-degraded after transferring its electron to the $\mathrm{CB}$ of the catalyst [13]. In addition, the irradiance of visible light used is much higher than that of the UVA light.

\subsection{Effect of operating parameters on the degradation of $A M$}

3.4a Effect of dye concentration: As can be seen in table 3, with increasing initial AM concentration from 5 to $25 \mathrm{mg} \mathrm{l}^{-1}$, DE decreases from 100 to $86.2 \%$ and from 100 to $89.5 \%$ for
AM degradation under visible and UVA light, respectively. With an increase in initial AM concentration, AM in the bulk of the suspension strongly absorbs incoming light. This leads to reduced light absorption by the catalyst and the generation of electron-hole pairs is then reduced.

3.4b Effect of catalyst concentration: For the photocatalytic degradation of $10 \mathrm{mg}^{-1}$ of AM under visible light, with an increase in catalyst concentration from 0.5 to $1 \mathrm{~g} \mathrm{l}^{-1}$, DE increases from 93.5 to $100 \%$. With further increase of catalyst concentration to $2.5 \mathrm{~g} \mathrm{l}^{-1}$, DE then decreases to $81.5 \%$. The same pattern is also observed for the photocatalytic degradation of AM under UVA light and the optimum catalyst concentration is found to be $1 \mathrm{~g} \mathrm{l}^{-1}$. This can be explained on the basis of two factors, the availability of active sites on the catalyst surface and the light penetration into the suspension system [14]. With an increase in catalyst concentration, the total active surface area increases and the suspension turbidity increases as well. As a result, the light scattering increases leading to decreased light penetration.

3.4c Effect of $p H: \quad \mathrm{pH}$ of the suspension system is considered to be a critical operating parameter in the photocatalytic degradation of organic compounds. It determines the surface charge of the catalyst particles, the size of formed aggregates, the charge of organic pollutants, the adsorption of organic pollutants onto the catalyst surface and the concentration of ${ }^{\circ} \mathrm{OH}$ radicals generated [15]. As seen in table 3, for the photocatalytic degradation of $10 \mathrm{mg} \mathrm{l}^{-1}$ of AM under visible light, $\mathrm{DE}$ is observed to be the same $(100 \%)$ with increasing $\mathrm{pH}$ from 5 to 7 . Further increase of $\mathrm{pH}$ from 7 to 9 decreases DE from 100 to $87.3 \%$. Similarly for the degradation of AM under UVA light, with an increase of $\mathrm{pH}$ from 5 to $7, \mathrm{DE}$ is in the same value of $100 \%$ and then decreases to $90.1 \%$ with further increase of $\mathrm{pH}$ to 9 . This can be explained as follows. The zero point charge $\mathrm{pH}$ of the catalyst is 2.1 (table 1). Therefore, the $\mathrm{N}-\mathrm{WO}_{3}$ surface is negatively charged above $\mathrm{pH}$ of 2.1. AM, as an anionic dye, is poorly adsorbed on the surface of $\mathrm{N}-\mathrm{WO}_{3}$ due to electrostatic repulsion by the negatively charged surface of the catalyst. With increasing $\mathrm{pH}$, this electrostatic repulsion is more significant and the adsorption of AM becomes less favourable. As a result, DE is greatly decreased.

Table 2. Efficiency of the catalysts for AM degradation.

\begin{tabular}{lccc}
\hline & & & DE $(\%)$ \\
\cline { 3 - 4 } Catalyst & Adsorption (\%) & Vis & UVA \\
\hline $\mathrm{WO}_{3}$ & $2.7(0.12)$ & $17.1(0.28)$ & $21.0(0.48)$ \\
$\mathrm{c} / \mathrm{WO}_{3}$ & $2.1(0.09)$ & $9.3(0.24)$ & $10.2(1.24)$ \\
$\mathrm{N}-\mathrm{WO}_{3}$ & $5.5(0.29)$ & $100(0)$ & $100(0)$ \\
$\mathrm{c} / \mathrm{N}-\mathrm{WO}_{3}$ & $3.5(0.18)$ & $28.3(3.42)$ & $23.5(0.36)$ \\
\hline
\end{tabular}

Conditions: catalyst concentration $(W)=1 \mathrm{~g} \mathrm{l}^{-1}$, AM concentration $\left(C_{0}\right)=5 \mathrm{mg} 1^{-1}, \mathrm{pH}=7$, time $(t)=1 \mathrm{~h}$.

Standard error is in parentheses. 
Table 3. Dye degradation efficiency at different operating parameters.

\begin{tabular}{|c|c|c|c|c|}
\hline \multirow[b]{2}{*}{ Parameter } & \multirow[b]{2}{*}{ Value } & \multicolumn{2}{|c|}{$\mathrm{DE}(\%)$} & \multirow[b]{2}{*}{ Fixed parameter } \\
\hline & & Vis & UVA & \\
\hline Dye concentration $\left(\mathrm{mg} \mathrm{l}^{-1}\right)$ & $\begin{array}{c}5 \\
10 \\
15 \\
20 \\
25\end{array}$ & $\begin{array}{c}100(0) \\
100(0) \\
94.5(1.93) \\
90.2(0.91) \\
86.2(4.39)\end{array}$ & $\begin{array}{c}100(0) \\
100(0) \\
96.6(0.16) \\
92.1(1.72) \\
89.5(3.37)\end{array}$ & $W=1 \mathrm{~g}^{-1}, \mathrm{pH}=7, t=1 \mathrm{~h}$ \\
\hline Catalyst concentration $\left(\mathrm{g}^{-1}\right)$ & $\begin{array}{c}0.5 \\
1 \\
1.5 \\
2 \\
2.5\end{array}$ & $\begin{array}{c}93.5(0.09) \\
100(0) \\
95.0(2.1) \\
90.9(0.29) \\
81.5(0.11)\end{array}$ & $\begin{array}{c}95.1(1.82) \\
100(0) \\
96.7(1.47) \\
88.3(0.32) \\
82.0(0.61)\end{array}$ & $C_{0}=10 \mathrm{mg} \mathrm{l}^{-1}, \mathrm{pH}=7, t=1 \mathrm{~h}$ \\
\hline $\mathrm{pH}$ & $\begin{array}{l}5 \\
6 \\
7 \\
8 \\
9\end{array}$ & $\begin{array}{c}100(0) \\
100(0) \\
100(0) \\
93.2(0.02) \\
87.3(1.75)\end{array}$ & $\begin{array}{c}100(0) \\
100(0) \\
100(0) \\
95.4(0.45) \\
90.1(0.66)\end{array}$ & $W=1 \mathrm{~g} \mathrm{l}^{-1}, C_{0}=10 \mathrm{mg} \mathrm{l}^{-1}, t=1 \mathrm{~h}$ \\
\hline $\mathrm{H}_{2} \mathrm{O}_{2}$ concentration $\left(\mathrm{g}^{-1}\right)$ & $\begin{array}{c}0 \\
0.1 \\
0.3 \\
0.5 \\
0.7\end{array}$ & $\begin{array}{c}86.2(4.39) \\
90.1(3.53) \\
98.4(0.43) \\
100(0) \\
96.2(2.6)\end{array}$ & $\begin{array}{c}89.5(3.37) \\
92.6(2.36) \\
97.3(0.67) \\
98.1(0.62) \\
100(0)\end{array}$ & $W=1 \mathrm{~g} \mathrm{l}^{-1}, C_{0}=25 \mathrm{mg} \mathrm{l}^{-1}, \mathrm{pH}=7, t=1 \mathrm{~h}$ \\
\hline
\end{tabular}

Standard error is in parentheses.

3.4d Effect of $\mathrm{H}_{2} \mathrm{O}_{2}$ concentration: Hydrogen peroxide is known to beneficially affect the photocatalytic degradation of organic compounds due to the generation of ${ }^{\circ} \mathrm{OH}$ radicals upon photolysis of $\mathrm{H}_{2} \mathrm{O}_{2}$ by UV light and the inhibition of electron-hole recombination due to its role as an irreversible electron acceptor [15]. However, it was also reported that an excess of $\mathrm{H}_{2} \mathrm{O}_{2}$ leads to competitive reactions that can inhibit the photocatalytic degradation process [16]. The holes generated by the catalyst may also be consumed by $\mathrm{H}_{2} \mathrm{O}_{2}$. A similar effect is observed in the degradation of $\mathrm{AM}$ by $\mathrm{N}-\mathrm{WO}_{3}$ under visible light. With increasing $\mathrm{H}_{2} \mathrm{O}_{2}$ concentration, DE increases up to an optimum value $\left(0.5 \mathrm{~g} \mathrm{l}^{-1}\right)$ and subsequently decreases. On the contrary, under UVA light, with increasing $\mathrm{H}_{2} \mathrm{O}_{2}$ concentration to $0.7 \mathrm{~g}^{-1}$, DE keeps increasing. This may be because $\mathrm{H}_{2} \mathrm{O}_{2}$ undergoes photolysis producing two additional ${ }^{\circ} \mathrm{OH}$ radicals, which can degrade the dye [17]. The effect of $\mathrm{H}_{2} \mathrm{O}_{2}$ on the AM degradation is found to depend on the type of light source used.

3.4e Effect of inorganic ions: The inhibitory effects of inorganic ions can be attributed to light screening, competitive adsorption to surface active sites, competition for photons, surface deposition of precipitates and elemental metals, radical and hole scavenging and direct reaction with the photocatalyst [18].

The inhibition orders of AM degradation by inorganic ions are determined based on the $k_{\text {app }}$ values, shown in table 4 and figure 3 . The inhibition of AM degradation by inorganic anions under visible light is in the following order:
Table 4. The $k_{\text {app }}$ in the presence of inorganic ions.

\begin{tabular}{lll}
\hline Inorganic ions & $k_{\text {app }}$ Vis $\left(\mathrm{min}^{-1}\right)$ & $k_{\text {app }} \mathrm{UVA}\left(\mathrm{min}^{-1}\right)$ \\
\hline $\mathrm{No}$ ion & $0.0339(0.0005)$ & $0.0381(0.0001)$ \\
$\mathrm{Cl}^{-}$ & $0.0290(0.0013)$ & $0.0246(0.0009)$ \\
$\mathrm{NO}_{3}^{-}$ & $0.0319(0.0005)$ & $0.0283(0.0007)$ \\
$\mathrm{CO}_{3}^{2-}$ & $0.0251(0.0001)$ & $0.0233(0.0008)$ \\
$\mathrm{SO}_{4}^{2-}$ & $0.0311(0.0005)$ & $0.0347(0.0002)$ \\
$\mathrm{NH}_{4}^{+}$ & $0.0335(0.0001)$ & $0.0372(0.0009)$ \\
$\mathrm{Ca}^{2+}$ & $0.0252(0.0001)$ & $0.0218(0.0003)$ \\
\hline
\end{tabular}

Conditions: $W=1 \mathrm{~g}^{-1}, C_{0}=25 \mathrm{mg}^{-1}, \mathrm{pH}=7$, ion concentration $=0.1 \mathrm{M}$.

Standard error is in parenthesis.

$\mathrm{CO}_{3}^{2-}>\mathrm{Cl}^{-}>\mathrm{SO}_{4}^{2-}>\mathrm{NO}_{3}^{-} \cdot \mathrm{CO}_{3}^{2-}$ inhibits the degradation of AM quite significantly. The first reason may be due to the weakening of AM adsorption on the catalyst surface. After adding $\mathrm{CO}_{3}^{2-}$, the catalyst surface becomes more negative due to increased suspension $\mathrm{pH}$. As a result, AM as an anionic species is repelled by the negatively charged surface of $\mathrm{N}-\mathrm{WO}_{3}$. The second reason is probably due to the scavenging character of $\mathrm{CO}_{3}^{2-}$ on the ${ }^{\circ} \mathrm{OH}$ radical as shown in equation (4) [19]:

$$
\mathrm{CO}_{3}^{2-}+{ }^{\bullet} \mathrm{OH} \rightarrow \mathrm{OH}^{-}+{ }^{\circ} \mathrm{CO}_{3}^{-}
$$



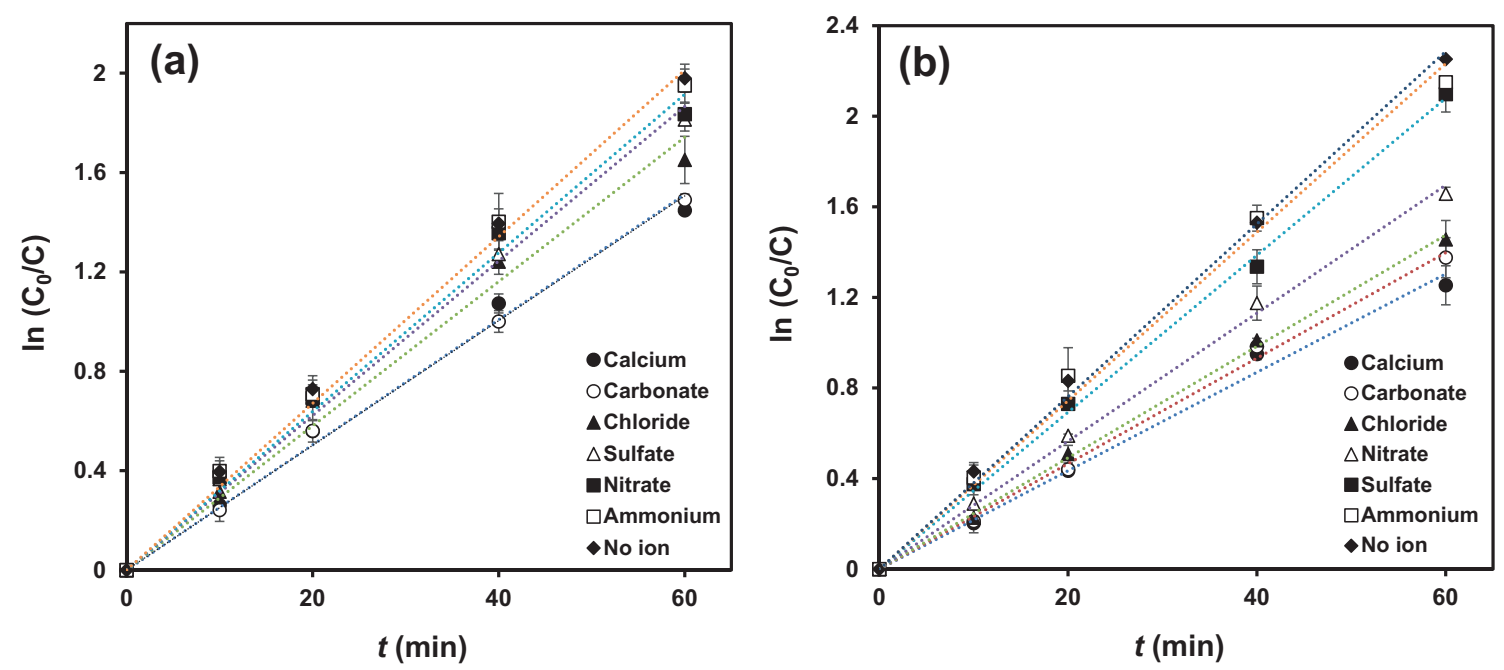

Figure 3. The kinetic plots for pseudo first-order reaction of $\mathrm{AM}$ degradation by $\mathrm{N}-\mathrm{WO}_{3}$ (a) under visible and (b) UVA light in the presence of inorganic ions $\left(W=1 \mathrm{~g} \mathrm{l}^{-1}, C_{0}=25 \mathrm{mg} \mathrm{l}^{-1}, \mathrm{pH}=7\right.$, ion concentration $\left.=0.1 \mathrm{M}\right)$. Error bars denote standard deviation.

One can see that the inhibitory effect of $\mathrm{Cl}^{-}$is lower than that of $\mathrm{CO}_{3}^{2-}$. The inhibition by $\mathrm{Cl}^{-}$can be due to the preferential adsorption displacement over the surface bound $\mathrm{OH}^{-}$ ions [20], which then reduces the generation of ${ }^{\circ} \mathrm{OH}$ radicals. The scavenging of the holes and ${ }^{\circ} \mathrm{OH}$ radicals (equations (5) and (6)) by $\mathrm{Cl}^{-}$may also inhibit the AM degradation [18]:

$$
\begin{aligned}
& \mathrm{Cl}^{-}+\mathrm{h}^{+} \rightarrow{ }^{\circ} \mathrm{Cl} \\
& \mathrm{Cl}^{-}+{ }^{\circ} \mathrm{OH} \rightarrow{ }^{\circ} \mathrm{Cl}+\mathrm{OH}^{-}
\end{aligned}
$$

Furthermore, the inhibitory effect of $\mathrm{SO}_{4}^{2-}$ is found to be lower than that of $\mathrm{Cl}^{-}$. Although $\mathrm{SO}_{4}^{2-}$ may also scavenge the holes and ${ }^{\circ} \mathrm{OH}$ radicals (equations (7) and (8)), it is greatly repelled by negatively charged $\mathrm{N}-\mathrm{WO}_{3}$ surface via electrostatic repulsion. Thus, there is no significant inhibition on the adsorption of AM.

$$
\begin{aligned}
& \mathrm{SO}_{4}^{2-}+\mathrm{h}^{+} \rightarrow{ }^{\cdot} \mathrm{SO}_{4}^{-} \\
& \mathrm{SO}_{4}^{2-}+{ }^{\circ} \mathrm{OH} \rightarrow{ }^{\circ} \mathrm{SO}_{4}^{-}+\mathrm{OH}^{-}
\end{aligned}
$$

As for $\mathrm{NO}_{3}^{-}$, it may compete for surface active sites that are involved in displacement over the surface bound $\mathrm{OH}^{-}$ions. However, it can be photolysed forming ${ }^{\circ} \mathrm{OH}$ radicals (equations (9), (10) and (11)) [21]. Therefore, the net result is a negligible inhibitory effect.

$$
\begin{aligned}
& \mathrm{NO}_{3}^{-}+h v \rightarrow\left[\mathrm{NO}_{3}^{-}\right]^{*} \\
& {\left[\mathrm{NO}_{3}^{-}\right]^{*} \rightarrow{ }^{\cdot} \mathrm{NO}_{2}+{ }^{\circ} \mathrm{O}^{-}} \\
& { }^{\circ}{ }^{-}+\mathrm{H}_{2} \mathrm{O} \rightarrow{ }^{\circ} \mathrm{OH}+\mathrm{OH}^{-}
\end{aligned}
$$

Under UVA light, the order of photocatalytic inhibition by the anions investigated is $\mathrm{CO}_{3}^{2-}>\mathrm{Cl}^{-}>\mathrm{NO}_{3}^{-}>\mathrm{SO}_{4}^{2-}$. The inhibition order under UVA light is found to be slightly different than that under visible light. This is due to the difference in the AM degradation mechanism. As seen, the inhibitory effect of $\mathrm{NO}_{3}^{-}$is found to be higher than that of $\mathrm{SO}_{4}^{2-}$. This may be due to the UV screening effect by $\mathrm{NO}_{3}^{-}$that inhibits the absorption of photons by the catalyst [22]. One can also see that the reduction of $k_{\text {app }}$ is more pronounced in the case of AM degradation under UVA light. This may be because under UVA light ${ }^{\circ} \mathrm{OH}$ is the dominant reactive species. Thus, the reaction of those inorganic ions with ${ }^{\circ} \mathrm{OH}$ results is significantly reduced $k_{\text {app }}$.

Under both visible and UVA light, the inhibitory effect of $\mathrm{NH}_{4}^{+}$is lower than that of $\mathrm{Ca}^{2+}$. $\mathrm{NH}_{4}^{+}$shows negligible effects since it is at its maximum oxidation state and thus is incapable of inhibiting the photocatalytic process. Although $\mathrm{Ca}^{2+}$ as well is at its maximum oxidation state, it may be reduced by the photogenerated electron and deposited on the catalyst surface. The deposition of $\mathrm{Ca}^{0}$ hinders the adsorption of AM. Additionally, the compression of the electrical double layer at a high $\mathrm{Ca}^{2+}$ concentration of $0.1 \mathrm{M}$ may induce catalyst aggregation and precipitation [23].

Overall, inorganic ions, such as $\mathrm{CO}_{3}^{2-}, \mathrm{Cl}^{-}$and $\mathrm{Ca}^{2+}$, which are ubiquitous components in textile effluents are found to negatively affect the photocatalytic performance of $\mathrm{N}-\mathrm{WO}_{3}$ in degrading AM. Hence, to achieve high degradation efficiency the concentration of such ions should be strictly controlled, especially $\mathrm{Ca}^{2+}$ and $\mathrm{CO}_{3}^{2-}$. The concentration of those ions should be less than $0.1 \mathrm{M}$.

\subsection{Mechanism of AM degradation by $\mathrm{N}-\mathrm{WO}_{3}$}

In the case of $\mathrm{N}-\mathrm{WO}_{3}$, the excitation of electrons upon irradiation takes place through different pathways: (1) electrons are excited from VB to CB via an energy level formed by oxygen 

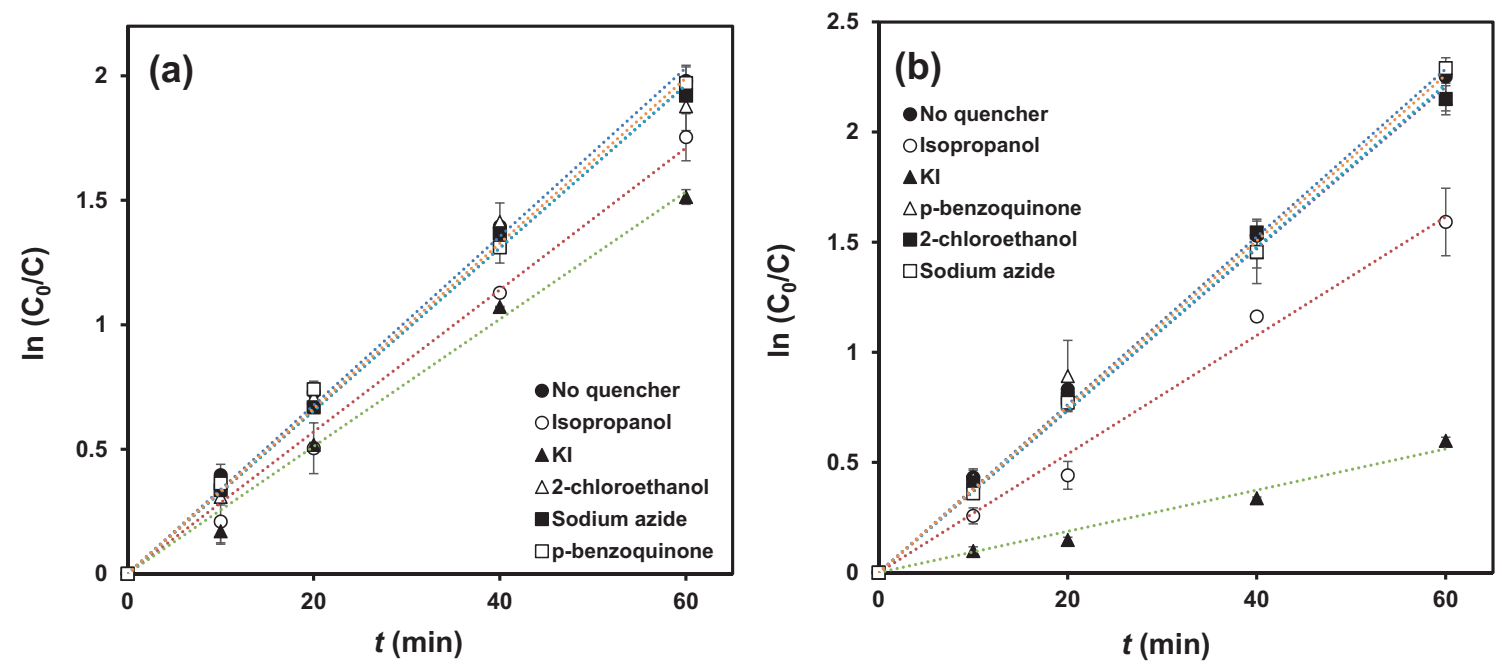

Figure 4. The kinetic plots for pseudo first-order reaction of $\mathrm{AM}$ degradation by $\mathrm{N}-\mathrm{WO}_{3}$ (a) under visible and (b) UVA light in the presence of quenchers ( $W=1 \mathrm{~g} \mathrm{l}^{-1}, C_{0}=25 \mathrm{mg} \mathrm{l}^{-1}, \mathrm{pH}=7$ ). Error bars denote standard deviation.

Table 5. The $k_{\text {app }}$ in the presence of quenchers.

\begin{tabular}{|c|c|c|c|c|c|}
\hline \multirow[b]{2}{*}{ Quencher } & \multirow[b]{2}{*}{ Quenched reactive species } & \multicolumn{2}{|c|}{ Vis/N-WO ${ }_{3}$} & \multicolumn{2}{|c|}{$\mathrm{UVA} / \mathrm{N}-\mathrm{WO}_{3}$} \\
\hline & & $k_{\text {app }}\left(\min ^{-1}\right)$ & $R(\%)$ & $k_{\text {app }}\left(\min ^{-1}\right)$ & $R(\%)$ \\
\hline No quencher & - & $0.0339(0.0005)$ & - & $0.0381(0.0001)$ & - \\
\hline $\mathrm{KI}$ & $\mathrm{h}^{+}$ & $0.0256(0.0003)$ & $24.4(2.30)$ & $0.0094(0.0002)$ & $75.2(0.78)$ \\
\hline Isopropanol & ${ }^{\circ} \mathrm{OH}$ & $0.0285(0.0012)$ & $15.8(5.15)$ & $0.0269(0.0012)$ & $29.6(5.63)$ \\
\hline $\mathrm{NaN}_{3}$ & ${ }^{1} \mathrm{O}_{2}$ & $0.0328(0.0001)$ & $3.3(1.82)$ & $0.0376(0.0001)$ & $1.3(0.01)$ \\
\hline 2-Chloroethanol & $\mathrm{e}^{-}$ & $0.0327(0.0004)$ & $3.5(2.86)$ & $0.0369(0.0009)$ & $2.9(1.48)$ \\
\hline$p$-Benzoquinone & $\mathrm{O}_{2}^{-}$ & $0.0332(0.0004)$ & $2.1(0.38)$ & $0.0367(0.0010)$ & $3.4(2.95)$ \\
\hline
\end{tabular}

Conditions: $W=1 \mathrm{~g} \mathrm{l}^{-1}, C_{0}=25 \mathrm{mg}^{-1}, \mathrm{pH}=7$.

Standard error is in parentheses.

The role of reactive species is in the following order:

Vis $/ \mathrm{N}-\mathrm{WO}_{3}: \mathrm{h}^{+}>{ }^{\bullet} \mathrm{OH}>\mathrm{e}^{-}>{ }^{1} \mathrm{O}_{2}>{ }^{\bullet} \mathrm{O}_{2}^{-}$.

$\mathrm{UVA} / \mathrm{N}-\mathrm{WO}_{3}: \mathrm{h}^{+}>{ }^{\bullet} \mathrm{OH}>{ }^{\bullet} \mathrm{O}_{2}^{-}>\mathrm{e}^{-}>{ }^{1} \mathrm{O}_{2}$.

vacancy $\left(\mathrm{O}_{\mathrm{v}}\right) ;(2)$ electrons are directly excited from VB to CB; (3) electrons are excited from VB to CB via a mid-band state of $2 p$ orbitals of $\mathrm{N}\left(\mathrm{N}_{2 \mathrm{p}}\right)$; (4) electrons are excited from $\mathrm{N}_{2 \mathrm{p}}$ to CB.

Upon visible light irradiation, the electrons in $\mathrm{AM}$ are excited and can be transferred to the $\mathrm{CB}$ of $\mathrm{N}-\mathrm{WO}_{3}$. This photosensitization mechanism involves electron transfer from the AM to the $\mathrm{N}-\mathrm{WO}_{3}$. After light absorption by the adsorbed $\mathrm{AM}$, an electron in $\mathrm{AM}$ is excited from the highest occupied molecular orbital (HOMO) to the lowest unoccupied molecular orbital (LUMO). This excited electron can be transferred to the $\mathrm{CB}$ of $\mathrm{N}-\mathrm{WO}_{3}$. This process is thermodynamically favourable due to the low $\mathrm{CB}$ potential of $\mathrm{N}-\mathrm{WO}_{3}$. The $\mathrm{CB}$ of $\mathrm{WO}_{3}$ is $+0.3 \mathrm{~V} v s$. NHE at $\mathrm{pH} 7$ [9].

It should be noted that the photocatalytic activity of $\mathrm{N}-\mathrm{WO}_{3}$ under visible light can also be due to the direct oxidation of $\mathrm{AM}$ by $\mathrm{h}^{+}$generated either in the mid-band gap state or in the VB. However, direct reduction of AM by $\mathrm{e}^{-}$is not likely to occur due to the lower $\mathrm{CB}$ potential of $\mathrm{N}-\mathrm{WO}_{3}$ as compared to the LUMO potential of AM. Moreover, due to the same reason of low $\mathrm{CB}$ potential in the case of pristine $\mathrm{WO}_{3}, \mathrm{e}^{-}$ accumulated in the $\mathrm{CB}$ cannot be consumed by the electron acceptors available in the system, such as $\mathrm{O}_{2}$ and $\mathrm{AM}$, and thus quickly recombines with $\mathrm{h}^{+}$in the VB. This results in low quantum efficiency. However, for $\mathrm{N}-\mathrm{WO}_{3}, \mathrm{e}^{-}$does not recombine with $\mathrm{h}^{+}$because it is trapped by $\mathrm{N}$ dopants, which acts as $\mathrm{e}^{-}$traps. As a result, the photocatalytic activity is greatly enhanced.

\subsection{Role of reactive species}

Photocatalytic activity of a catalyst depends not only on light absorption ability, but also on types of reactive species produced. This is because reactive species have different oxidation and reduction powers. To elucidate the role of reactive species during the degradation of AM, chemical quenching techniques were employed [10]. 
As seen in figure 4, the AM degradation by $\mathrm{N}-\mathrm{WO}_{3}$ in the presence of quenchers under visible and UVA light follows a pseudo first-order kinetic model. Table 5 shows the $k_{\text {app }}$, with or without the presence of the quenchers. With the addition of quenchers, the $k_{\text {app }}$ is found to decrease. Under both visible and UVA light, a significant role of $\mathrm{h}^{+}$is observed. This is because upon irradiation, $\mathrm{h}^{+}$is generated not only in the VB, but also in the mid-gap state formed by the $\mathrm{N}$ dopant $\left(\mathrm{N}_{2 \mathrm{p}}\right)$. The $\mathrm{h}^{+}$participates in the photocatalytic degradation process by directly attacking AM on the catalyst surface. Small reductions of $k_{\text {app }}$ with the addition of $\left(\mathrm{CH}_{3}\right)_{2} \mathrm{CHOH}$ suggest that ${ }^{\circ} \mathrm{OH}$ contributes to the degradation of $\mathrm{AM}$ to a lesser extent. Negligible inhibition of $k_{\text {app }}$ with the addition of $\mathrm{NaN}_{3}$, p-benzoquinone and $\mathrm{Cl}\left(\mathrm{CH}_{2}\right)_{2} \mathrm{OH}$ suggests that ${ }^{1} \mathrm{O}_{2},{ }^{\circ} \mathrm{O}_{2}^{-}$and $\mathrm{e}^{-}$have a very minor role in the $\mathrm{AM}$ degradation. The minor roles of ${ }^{1} \mathrm{O}_{2}$ and ${ }^{\circ} \mathrm{O}_{2}^{-}$are due to the lower $\mathrm{CB}$ edge of $\mathrm{N}-\mathrm{WO}_{3}$. As a result, the one-electron reduction process, which generates ${ }^{\circ} \mathrm{O}_{2}^{-}$from the reaction between $\mathrm{O}_{2}$ and $\mathrm{e}^{-}$cannot occur. Due to unavailability of ${ }^{\circ} \mathrm{O}_{2}^{-}, \mathrm{h}^{+}$cannot react with ${ }^{\circ} \mathrm{O}_{2}^{-}$to produce ${ }^{1} \mathrm{O}_{2}$.

It is important to note that the role of $\mathrm{h}^{+}$under visible light is less significant than that under UVA light. This indicates that dye sensitization mechanism is the major pathway for the degradation of AM under visible light instead of dye oxidation by reactive radicals. The existence of dye sensitization as the major pathway is supported by the fact that this sensitization process is thermodynamically highly favourable. During the sensitization process, an excited electron from the LUMO of AM can be easily transferred to the $\mathrm{CB}$ of $\mathrm{N}-\mathrm{WO}_{3}$ due to considerably low $\mathrm{CB}$ potential of $\mathrm{N}-\mathrm{WO}_{3}$. In contrast, oxidation of AM by reactive radicals is the main pathway for AM degradation under UVA light as dye sensitization cannot occur under UV light.

\section{Conclusions}

$\mathrm{N}$-doped $\mathrm{WO}_{3}$ photocatalyst is successfully synthesized by thermal decomposition of peroxotungstic acid-urea complex and is evaluated for the degradation of toxic dye AM. N doping into $\mathrm{WO}_{3}$ greatly enhances the photocatalytic activity for the AM degradation. The quenching experiment shows the negligible role of ${ }^{\circ} \mathrm{O}_{2}^{-}$in the $\mathrm{AM}$ degradation under visible and UVA light. This indicates the absence of the one-electron transfer mechanism due to the unsuitability of the CB potential for $\mathrm{O}_{2}$ reduction. $\mathrm{h}^{+}$plays a key role in the degradation of AM under visible and UVA light, while ${ }^{\circ} \mathrm{OH}$ contributes to a lesser extent. The dye sensitization mechanism is the main pathway for the degradation of AM under visible light. This is due to the considerably low $\mathrm{CB}$ potential of $\mathrm{N}-\mathrm{WO}_{3}$ allowing efficient electron transfer from AM to the CB. Under UVA light, $\mathrm{AM}$ is degraded mainly through oxidation by $\mathrm{h}^{+}$. This is due to the very deep VB potential of $\mathrm{N}-\mathrm{WO}_{3}$, capable of generating $\mathrm{h}^{+}$with strong oxidation power. Using $1 \mathrm{~g} \mathrm{l}^{-1}$ of $\mathrm{N}-\mathrm{WO}_{3}, 10 \mathrm{mg} \mathrm{l}^{-1}$ of AM can be degraded with $100 \%$ efficiency within $1 \mathrm{~h}$ at $\mathrm{pH} 7$ under both visible and UVA light.
Moreover, $\mathrm{CO}_{3}^{2-}, \mathrm{Cl}^{-}, \mathrm{NO}_{3}^{-}, \mathrm{SO}_{4}^{2-}$ and $\mathrm{Ca}^{2+}$ are found to inhibit the degradation of $\mathrm{AM}$, while $\mathrm{NH}_{4}^{+}$shows negligible influence.

\section{Acknowledgements}

This work is supported by the Sirindhorn International Institute of Technology through an Excellent Foreign Student (EFS) doctoral scholarship.

\section{References}

[1] Xin G, Guo W and Ma T 2009 Appl. Surf. Sci. 256165

[2] Bamwenda G R and Arakawa H 2001 Appl. Catal. A: Gen. 210 181

[3] Morales W, Cason M, Aina O, de Tacconi N R and Rajeshwar K 2008 J. Am. Chem. Soc. 1306318

[4] Miyauchi M 2008 Phys. Chem. Chem. Phys. 106258

[5] Bamwenda G R, Sayama K and Arakawa H 1999 J. Photochem. Photobiol. A: Chem. 122175

[6] Abe R, Takami H, Murakami N and Ohtani B 2008 J. Am. Chem. Soc. 1307780

[7] Arai T, Horiguchi M, Yanagida M, Gunji T, Sugihara H and Sayama K 2008 Chem. Commun. 5565 https://doi.org/10. 1039/B811657A

[8] Arai T, Horiguchi M, Yanagida M, Gunji T, Sugihara H and Sayama K 2009 J. Phys. Chem. C 1136602

[9] Kim J, Lee C W and Choi W 2010 Environ. Sci. Technol. 44 6849

[10] Antonopoulou M, Giannakas A, Deligiannakis Y and Konstantinou I 2013 Chem. Eng. J. 231314

[11] Wang D, Li Y, Puma G L, Wang C, Wang P, Zhang W et al 2015 J. Hazardous Mater. 285277

[12] Nogueira H I, Cavaleiro A M, Rocha J, Trindade T and de Jesus J D P 2004 Mater. Res. Bull. 39683

[13] Banerjee S, Pillai S C, Falaras P, O'shea K E, Byrne J A and Dionysiou D D 2014 J. Phys. Chem. Lett. 52543

[14] Daneshvar N, Salari D and Khataee A 2004 J. Photochem. Photobiol. A: Chem. 162317

[15] Sun J, Qiao L, Sun S and Wang G 2008 J. Hazardous Mater. 155312

[16] Daneshvar N, Salari D and Khataee A 2003 J. Photochem. Photobiol. A: Chem. 157111

[17] Stefan M I, Hoy A R and Bolton J R 1996 Environ. Sci. Technol. 302382

[18] Chong M N, Jin B, Chow C W and Saint C 2010 Water Res. 442997

[19] Guillard C, Lachheb H, Houas A, Ksibi M, Elaloui E and Herrmann J-M 2003 J. Photochem. Photobiol. A: Chem. 15827

[20] Wang D, Li Y, Li G, Wang C, Zhang W and Wang Q 2013 J. Hazardous Mater. 25464

[21] Zhang X, Wang Y and Li G 2005 J. Mol. Catal. A: Chem. 237 199

[22] Burns R A, Crittenden J C, Hand D W, Selzer V H, Sutter L L and Salman S R 1999 J. Environ. Eng. 12577

[23] Thio B J R, Montes M O, Mahmoud M A, Lee D-W, Zhou D and Keller A A 2011 Environ. Sci. Technol. 466985 